\title{
Chromatin state marks cell-type- and gender-specific replication of the Drosophila genome
}

\author{
Michaela Schwaiger, Michael B. Stadler, Oliver Bell, Hubertus Kohler, Edward J. Oakeley, \\ and Dirk Schübeler ${ }^{1}$ \\ Friedrich Miescher Institute for Biomedical Research, CH-4058 Basel, Switzerland
}

\begin{abstract}
Duplication of eukaryotic genomes during $S$ phase is coordinated in space and time. In order to identify zones of initiation and cell-type- as well as gender-specific plasticity of DNA replication, we profiled replication timing, histone acetylation, and transcription throughout the Drosophila genome. We observed two waves of replication initiation with many distinct zones firing in early-S phase and multiple, less defined peaks at the end of $S$ phase, suggesting that initiation becomes more promiscuous in late-S phase. A comparison of different cell types revealed widespread plasticity of replication timing on autosomes. Most occur in large regions, but only half coincide with local differences in transcription. In contrast to confined autosomal differences, a global shift in replication timing occurs throughout the single male $\mathrm{X}$ chromosome. Unlike in females, the dosage-compensated $\mathrm{X}$ chromosome replicates almost exclusively early. This difference occurs at sites that are not transcriptionally hyperactivated, but show increased acetylation of Lys 16 of histone $\mathrm{H} 4$ (H4K16ac). This suggests a transcription-independent, yet chromosome-wide process related to chromatin. Importantly, H4K16ac is also enriched at initiation zones as well as early replicating regions on autosomes during $S$ phase. Together, our study reveals novel organizational principles of DNA replication of the Drosophila genome and suggests that H4K16ac is more closely correlated with replication timing than is transcription.
\end{abstract}

[Keywords: Chromatin; Drosophila; microarray; replication]

Supplemental material is available at http://www.genesdev.org.

Received October 24, 2008; revised version accepted January 26, 2009.

Duplication of the genome during $S$ phase occurs in an ordered fashion as each sequence has to be replicated once per cell cycle. Most cell types have a temporally regulated program of genome duplication, where distinct chromosomal regions replicate at defined time points in S phase (Aladjem 2007). The coordinated completion of replication of all, even very late replicating sequences, is crucial, especially since the existence of a checkpoint for genome duplication and completion of $S$ phase in yeast has recently been put in question (Torres-Rosell et al. 2007).

The replication timing of a given sequence is defined by its distance to the closest origin and by the time of firing of that origin. The measurement of replication timing can infer zones of initiation as regions that replicate earlier than their genomic neighborhood. This was used to identify origins throughout the Saccharomyces cerevisiae genome (Raghuraman et al. 2001), where initiation occurs at defined sites that share consensus motifs (Nieduszynski et al. 2006). In higher eukaryotes only

${ }^{1}$ Corresponding author.

E-MAIL dirk@fmi.ch; FAX 41-61-6973976.

Article is online at http://www.genesdev.org/cgi/doi/10.1101/gad.511809. few sites of initiation have been mapped, and many initiation events occur in broad initiation zones containing multiple origins (Dijkwel et al. 2000; Zhou et al. 2002). Recently, early firing origins on a Drosophila chromosome (MacAlpine et al. 2004) and several mammalian origins (Lucas et al. 2007) have been identified using microarray technology. This, however, revealed no consensus sequence predictive of metazoan origins of replication, even though the proteins that bind to origins are highly conserved between yeast and metazoans (Aladjem 2007). It has been speculated that epigenetic or structural features could determine the initiation of DNA replication, which in turn could explain dynamics in replication timing.

Early microscopic studies have shown that condensed heterochromatin replicates later during $S$ phase than euchromatin (Gilbert 2002). The first genome-wide replication timing study in $S$. cerevisiae found no correlation between replication timing and transcription (Raghuraman et al. 2001). On the other hand, early replication was correlated with sites of transcription in metazoans, as revealed by similar genome-wide studies of replication timing and transcription in Drosophila (Schübeler et al. 
2002; MacAlpine et al. 2004) and human cells (White et al. 2004; Woodfine et al. 2004). Importantly, while highly significant, this correlation is not absolute. For example, in Drosophila, $30 \%$ of late replicating genes are active and $30 \%$ of early replicating genes are inactive. This high frequency of exceptions and the lack of experimental data for different Drosophila cell types make it impossible to predict the extent of differential replication timing relative to development-specific expression.

In mammalian cells, several single-gene examples of changes in replication timing or replication initiation with expression have been reported during differentiation (Hiratani et al. 2004; Perry et al. 2004; Norio et al. 2005; Gregoire et al. 2006). In addition, allelic differences in replication timing at imprinted genes and during $\mathrm{X}$ inactivation in mammalian cells have been described (Gilbert 2002). A comprehensive comparison of the generich human chromosome 22 between two cell types did not reveal widespread differences in replication timing (White et al. 2004), while a very recent analysis of mouse embryonic stem cells showed widespread changes in replication domain organization during cellular differentiation, which in part localize to differentially expressed genes (Hiratani et al. 2008).

It is well established that active transcription always coincides with several characteristic histone modifications (Schübeler et al. 2004; Liu et al. 2005). Thus, a potential mechanistic link between changes in transcription and switches in replication timing may be chromatin structure (Schwaiger and Schübeler 2006). Indeed, early replication has been linked to active chromatin modifications, such as histone acetylation (Vogelauer et al. 2002; Aparicio et al. 2004; Schübeler et al. 2004; Hiratani et al. 2008). For example, the human $\beta$-globin locus replicates late in most cell types, but early in the cells where it is expressed. Upon deletion of the distal enhancer of the locus, open chromatin persists, and the region still replicates early, even though it is not expressed (Cimbora et al. 2000; Schübeler et al. 2000). This particular case would imply that replication timing is more tightly linked to chromatin than to transcription. Furthermore, it suggests that an open chromatin conformation might poise an entire region for early replication, as has been suggested for other multigene loci (Schwaiger and Schübeler 2006).

In this study, we created high-resolution replication timing profiles in Drosophila cells of different gender and compared them with histone acetylation and transcription. This allowed us to approximate the location of initiation zones throughout $S$ phase. The comparison of two cell types revealed a connection between replication timing differences that occur in large regions and localized differences in gene expression. In addition, we discovered a global shift in replication timing on the dosage-compensated X chromosome in male Drosophila cells. This shift in replication timing to earlier replication reflects H4K16 acetylation, a chromatin modification characteristic of open, active domains, which we find also enriched at initiation zones on autosomes. Together, these findings reveal a detailed picture of the organization of replication timing and imply a connection between chromatin structure and the replication program.

\section{Results}

High-resolution replication timing analysis of the Drosophila genome

A replication timing profile of sufficient temporal and spatial resolution is required to determine size and structure of replication domains. We applied an S-phase fractionation assay to determine replication timing in Drosophila cells, where nonsynchronized cells are pulselabeled with BrdU and sorted into different S-phase fractions (Gilbert and Cohen 1987). Replicating DNA in each fraction is isolated by immunoprecipitation with an antibody against BrdU (Hansen et al. 1993). To measure the temporal resolution of the assay, we sorted cells into three equal parts of S phase (early, mid, and late) and quantified enrichments of replicating DNA in each fraction at a set of genes and a repetitive element (Fig. 1A,B). As demonstrated previously in mammalian cells /Cimbora et al. 2000), we observe a distinct peak of enrichment for every sequence, indicative of a defined time of replication. Yet each sequence can also be detected at lower levels at other time points in S phase. As a consequence, an early replicating gene is about 10 -fold more abundant in the earliest over the latest fraction. A mid-Sphase replicating sequence such as the CG9743 gene (Fig. 1B) peaks in the central fraction but can also be detected at lower levels in early- and late-S phase. Its mid-S-phase replication can thus also be inferred by its presence in the early and late fractions (Fig. 1C). Such broad distribution of replication timing around the peak results from combining the timing patterns of 60,000 nonsynchronized cells in each sorted fraction. This integration of many cells creates a temporal resolution higher than could be obtained measuring only a single cell with this assay. It furthermore allows us to infer the timing of all tested sequences by considering only the early and late fractions (Fig. 1B,C).

We hybridized these two fractions enriched for early and late replicating DNA to Affymetrix arrays that cover the whole genome with 25-mer oligonucleotide probes separated by 10 base pairs (bp). From the array measurements, replication timing was calculated as the ratio of signal of the early versus the late replicating DNA as previously described (Schübeler et al. 2002). This global profile proved to be highly reproducible between biological replicates (Supplemental Fig. 1A,F) and independent of using either the Affymetrix or Nimblegen microarray platform for detection (Supplemental Fig. 1B). Single-gene qPCR controls of 25 amplicons confirmed array predictions $(r=0.95)$ (Fig. 1D; Supplemental Fig. 1E), and no sequence bias in array detection was observed (Supplemental Fig. 1D). As a further test of our approach of comparing early and late replicating DNA, we performed experiments in which we hybridized BrdU-containing DNA from four separate fractions covering all of $S$ phase to Affymetrix tiling arrays. Similarly to the PCR controls 
shown in Figure 1B, these genome-wide profiles confirmed the timing predictions that are based on comparing early versus late replicating DNA (Supplemental Figs. 2, 3).

Figure 2A shows the timing values and profile for a representative region. As is evident from this section, neighboring data points tend to have similar replication timing values. This spatial dependency is expected as replication timing does not change between proximal sequences. The similarity of neighboring probes can be quantified statistically as it results in very high autocor-

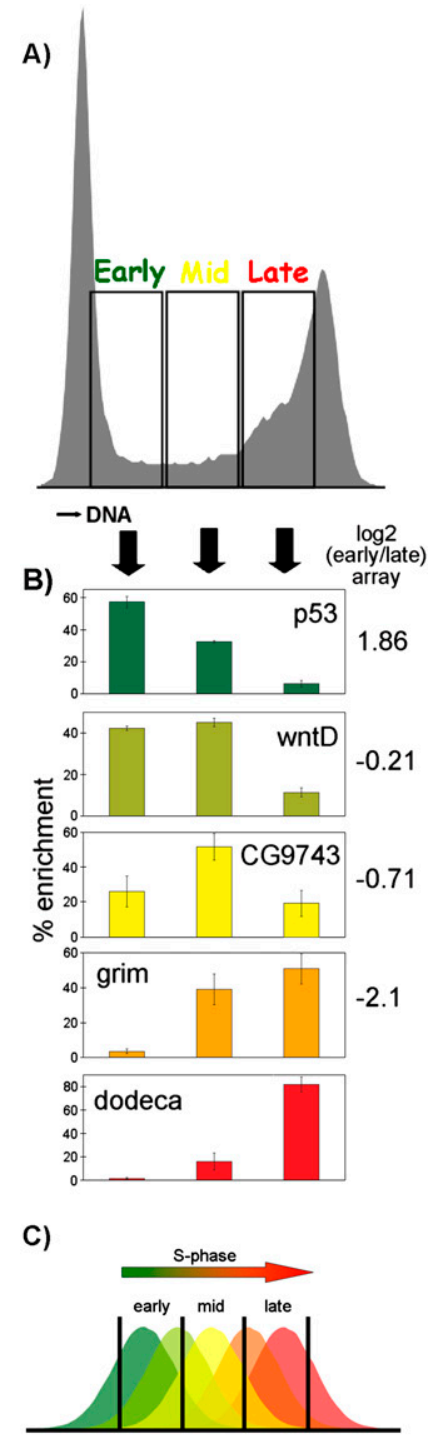

D)

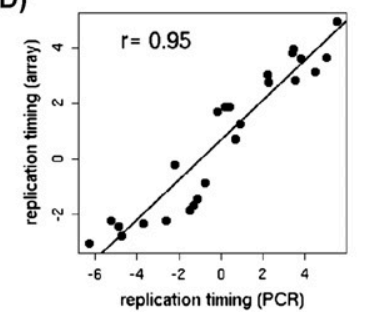

relation, which extends up to $\sim 200 \mathrm{~kb}$ (Supplemental Fig. 1C). This finding confirms the previous observation that regions of similar replication timing tend to be $\sim 180 \mathrm{~kb}$ in Drosophila (MacAlpine et al. 2004). They are nonetheless an order of magnitude smaller than those in mammalian cells, which extend over megabase pairs (White et al. 2004; Woodfine et al. 2005; Hiratani et al. 2008).

\section{Structure and distribution of replication domains}

A zone of replication initiation replicates earlier than its upstream and downstream neighboring sequences. Consequently, replication timing can indicate where initiation occurs. This has already been shown for the yeast genome (Raghuraman et al. 2001) and at lower resolution for computationally predicted human origins (Woodfine et al. 2005; Audit et al. 2007). Indeed, zones of initiation appear as peaks in the replication timing profile, and the time of appearance of a peak during $S$ phase reflects its time of initiation. Conversely, a valley in the replication timing profile represents a zone where replication forks converge and replication terminates. We used our highresolution replication timing profile to define such initiation and termination zones genome-wide (Fig. 2A; Supplemental Figs. 3, 4; see the Supplemental Material).

This analysis identified broad zones of initiation, which are expected to contain at least one active origin. To validate this approach, we determined if peaks are enriched in small nascent strands that can only be detected proximal to active origins (Aladjem et al. 1998). We isolated nascent DNA fragments from logarithmically growing cells by alkaline gel electrophoresis (Gray et al. 2007). Within this fraction, we enrich for a control sequence of a previously described origin (Supplemental Fig. 4A; Sasaki et al. 1999; MacAlpine et al. 2004). After hybridizing nascent DNA to tiling arrays, we observed a significant enrichment of nascent DNA in initiation zones compared with termination zones (Fig. 2B; Supplemental Fig. 4H). Moreover, we recovered $87 \%$ of all previously mapped early replication origins on chromosome 2L (Supplemental Fig. 4B,H; MacAlpine et al.

Figure 1. High-resolution replication timing analysis in Drosophila cells. (A) DNA content profile of Kc cells. The FACS sorting-gates for early-, mid-, and late-S phase are indicated. The $X$-axis denotes DNA content and the $Y$-axis cell count. $(B)$ Enrichments of BrdU-containing DNA in each sorted fraction as quantified by qPCR. Four genes and a pericentric repeat sequence are shown that replicate at different times. As expected, the heterochromatic repeat replicated later than all tested genes. Note that in all genes the relative replication timing can be correctly inferred from measuring only the early and late fraction by using qPCR (bar graphs) or microarrays [ $\log _{2}$ (early/late) array]. This is also the case for mid-replicating sequences such as CG9743. Error bars represent the standard deviations between biological repeats. $(C)$ Graphical illustration of the broad distribution of replication timing patterns over the sorted regions allowing us to obtain continuous timing information by considering the early and late fractions. (D) Analysis of 25 single-gene controls quantified by qPCR compared with microarray measurements. Both methods show strong correlation $(r=0.95)$ reflecting high accuracy of array measurements. 
Figure 2. Distribution of zones of replication initiation and replication fork termination. (A) Shown are the replication timing values for a representative region of chromosome $2 \mathrm{~L}$ in Kc cells. Initiation zones manifest as peaks, and regions of fork termination as valleys. Several of these are indicated on this profile. Individual dots represent raw replication timing values and the black line represents the loess-smoothed replication timing profile. The $Y$-axis denotes the replication timing ratio and the $X$-axis the chromosomal position in base pairs. (B) Initiation zones are enriched for small nascent strand DNA. Shown is a density plot comparing enrichments of small nascent strands in timing-defined initiation versus termination zones. This analysis shows that initiation zones are enriched in small nascent DNA compared with termination zones $(P<$ 2.2e-16). The $P$-value was calculated using the Wilcoxon rank-sum test. $(C)$ Histogram displaying the frequency of timing-defined initiation zones throughout $\mathrm{S}$ phase,

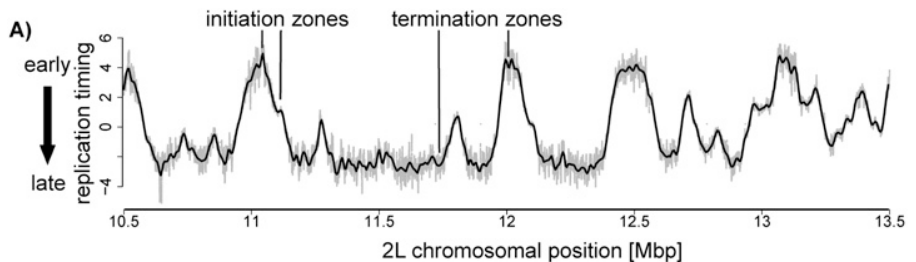

B) $\infty$ - initiation zones
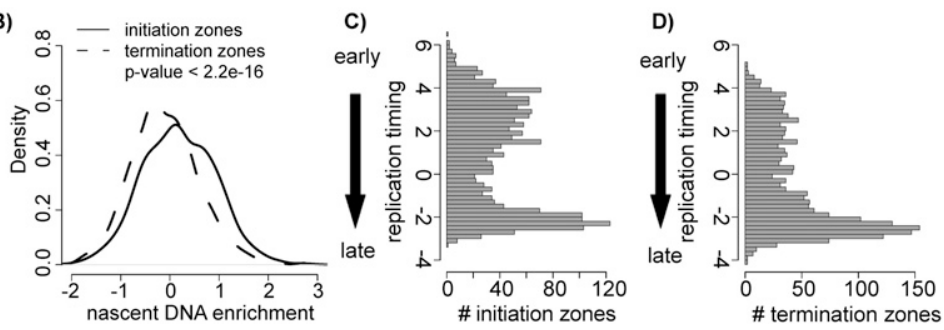
which reveals reduced initiation events in mid-S phase. $(D)$ Histogram displaying the frequency of timing-defined termination zones throughout $S$ phase, revealing increased fork convergence events toward late-S phase.

2004). Thus, several lines of evidence suggest that our procedure identifies regions containing sites of active initiation.

We next scored the frequency of such initiation zones throughout $S$ phase. To this end, we quantified the abundance of initiation and termination zones at different time points (Fig. 2C,D). A high number of initiation zones is detected in early-S phase, while their frequency declines toward mid-S phase. Interestingly, in late-S phase, the number of initiation zones increases (Fig. $2 \mathrm{C})$. This suggests that, at the level of the genome, initiation of DNA replication occurs throughout S phase yet with increased frequency of initiation events during early- and late-S phase.

Importantly, this finding is not a consequence of comparing early versus late replicating DNA. The same replication timing profile and peak locations are confirmed by analyzing replicating DNA from four S-phase fractions (Supplemental Fig. 3).

The distribution of termination zones, however, is different compared with initiation zones (Fig. 2D). Termination zones are distributed in equally low amounts in early- and mid-S phase but become very abundant in late$S$ phase (Fig. 2D). This discrepancy in the temporal occurrence of initiation and termination suggests that early initiating forks progress over longer distances before they converge compared with late initiating forks.

To test this prediction, we measured the length of replication domains as the distance between two termination zones, which by definition contain an initiation zone. In turn, the resulting length of such a replication domain reflects the chromosomal distance replicated by forks originating from one initiation zone (Supplemental Fig. 4C). This analysis reveals that early initiating replication domains are on average larger ( $80 \mathrm{~kb}$ vs. $30 \mathrm{~kb}$ ) than late initiating domains (Supplemental Fig. 4C). Together with the observation that the highest number of termination zones occurs in late-S phase (Fig. 2D), this also means that in Drosophila many replication domains extend until late-S phase (Fig. 2A).
Overall, we find that late initiating domains are greater in number than early initiating domains, yet each replicates a smaller region. Furthermore, as shown in Figure $2 \mathrm{~A}$, we identified large regions that replicate late, which consist of clustered late replicating domains. In summary, replication timing across the Drosophila genome shows many zones of initiation in early-S phase, and fewer in mid-S phase. Replication from those initiation zones frequently continues until late-S phase, where many replication forks converge. Interestingly, large, late replicating regions contain a high number of late initiating zones that reside in close proximity.

\section{Cell-type-specific differences in replication timing}

To define what fraction of the replication timing program differs between distinct cell types, we compared replication timing between two different Drosophila cell lines. Kc cells are derived from embryos (Echalier 1997), and their transcriptome is similar to embryonic tissue (Greil et al. 2003), while Cl8 cells were isolated from wing imaginal discs of third-instar larvae (Peel et al. 1990). In addition, we determined transcription in both cell types using $3^{\prime}$ untranslated region (UTR) as well as chromosomal tiling arrays (see the Materials and Methods). To determine regions of dynamic replication in an unbiased way, we used a three-state Hidden Markov Model (HMM) to segment replication timing differences between both cell types (see the Supplemental Material). In order to focus on robust changes, we excluded regional differences that are smaller than $20 \mathrm{~kb}$ or where the difference in timing extends over $<25 \%$ of the total range $\left(\Delta \log _{2}<1.74\right)$. These stringent criteria reveal 95 regions, corresponding to $12 \%$ of the genome on autosomes, that replicate earlier in $\mathrm{Kc}$ than in $\mathrm{Cl} 8$ cells (E:L) and 78 regions, corresponding to $9 \%$ of the genome on autosomes, that replicate earlier in Cl8 than in Kc cells (L:E) (Fig. 3A). These differentially replicating regions can be larger than $300 \mathrm{~kb}$, have an average size of $100 \mathrm{~kb}$ (data not shown), and represent $21 \%$ 

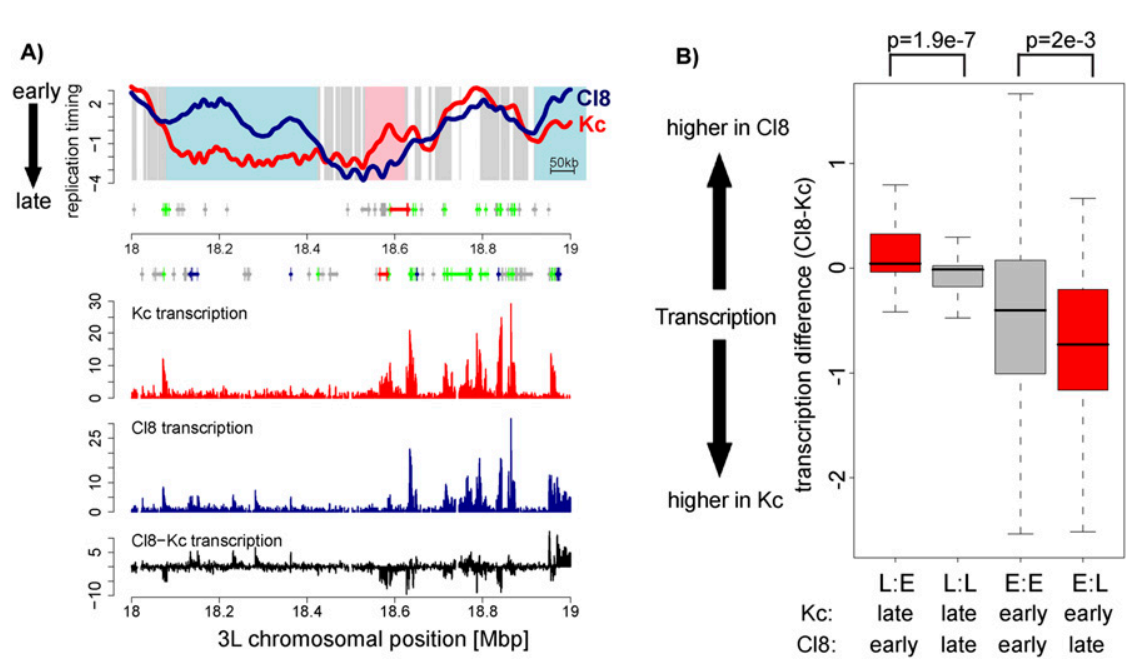

Figure 3. Differences in replication timing correlate frequently with transcription differences. (A) Replication timing profiles of $\mathrm{Kc}$ (red) and $\mathrm{Cl} 8$ (blue) cells for a representative region on chromosome $3 \mathrm{~L}$. The $X$ axis is the $3 \mathrm{~L}$ chromosomal position in megabase pairs, the $Y$-axis $\log _{2}$ (early/late replication). Background coloring denotes regions that replicate earlier in $\mathrm{Cl} 8$ cells (L:E, blue), regions that replicate earlier in Kc cells (E:L, pink), and regions replicating similarly in both cell types (gray). Regions with small differences over short regions were not included in further analysis (white, see methods for details). Annotated genes are displayed below the profile ([boxes] exons, [lines] introns, [small boxes] UTRs) and colored by their expression status (based on Affymetrix expression arrays; see the Supplemental Material;

[green] expressed in $\mathrm{Kc}$ and $\mathrm{Cl} 8$ cells, [blue] expressed only in $\mathrm{Cl} 8$ cells, [red] expressed only in Kc cells, [gray] not expressed in Kc and $\mathrm{Cl} 8$ cells). Transcription levels of $\mathrm{Kc}$ (red) and $\mathrm{Cl} 8$ (blue) cells measured by Affymetrix tiling arrays are displayed on the same scale below, including transcription level differences (black). (B) Distribution of transcription differences for regions with differential replication timing on autosomes. The boxplots illustrate that on average differences in replication timing coincide with changes in transcription. Transcriptional differences are calculated within HMM defined regions of differential replication timing and calculated as transcription $\mathrm{Cl} 8$ minus transcription $\mathrm{Kc}\left(\log _{2}\right)$. (L:E) Regions replicating earlier in Cl8 cells; (L:L) regions replicating late in both cell types; (E:E) regions replicating early in both cell types; (E:L) regions replicating earlier in Kc cells. $P$-values were calculated using the Wilcoxon rank-sum test.

of autosomal sequences. They often contain multiple replication domains, suggesting that their initiation is regulated in a coordinated manner (Supplemental Fig. 4C).

\section{Dynamic replication timing on autosomes correlates with differential gene expression}

In both $\mathrm{Kc}$ and $\mathrm{Cl} 8$ cell types, replication timing correlates with transcriptional activity (Supplemental Fig. $5 \mathrm{~A}, \mathrm{~B}, \mathrm{G})$. In many cases, such as in the examples shown in Figure 3A, transcription in a differentially replicating region is higher in the cell type where this region replicates earlier. A genome-wide comparison of average transcription differences to replication timing (Fig. 3B) reveals that regions that replicate earlier in Cl8 cells (L:E) tend to also be transcribed at a higher level in these cells. Similarly, regions that replicate earlier in Kc cells (E:L) show on average increased transcription in Kc cells (Fig. 3B; Supplemental Fig. 6A). Notably, in many cases, these transcriptional changes only occur at a low percentage of genes in each differentially replicating region (Supplemental Fig. 6A).

At the same time, we do not detect such transcriptional changes in about half of differentially replicating regions, and thus transcription cannot be the sole determining force (Fig. 3B; Supplemental Fig. 6A). Interestingly, genes that are transcriptionally inactive in both cell types but that replicate earlier in $\mathrm{Cl} 8$ cells are enriched for genes related to wing imaginal disc development (Table 1). $\mathrm{Cl} 8$ cells are derived from imaginal discs, and thus early replication of genes involved in wing development, such as the wingless gene (wg) (Supplemental Fig. 6B), might reflect an open chromatin state poised for subsequent activation. Taken together, this cell type comparison of transcription and replication timing reveals evidence for both transcription-dependent and transcription-independent pathways that affect replication timing.

To test how replication timing differences correlate with the binding of RNA Polymerase II, we generated genome-wide RNA Polymerase II-binding profiles. We observed a correlation between replication timing and RNA Polymerase II binding in both cell types (Supplemental Fig. 5E,F). Furthermore, as expected from the analysis of differential transcription, L:E regions showed more RNA Polymerase II in Cl8 cells, and E:L regions had higher RNA Polymerase II levels in Kc cells (Supplemental Fig. 6C). Interestingly, the correlation between replication timing and RNA Polymerase II binding is not as high as between replication timing and transcription (Supplemental Figs. 5E,F,H, 6C). This might be due to the fact that many inactive genes have paused RNA Polymerase II residing at their promoter (Muse et al. 2007; Zeitlinger et al. 2007), which might not lead to the chromatin changes linked to productive elongation.

\section{Gender-specific replication timing-absence of late replication on the male $X$ chromosome}

A comparison of the timing profiles between both cell types revealed a remarkable difference for the X chromosomes. In female Kc cells, replication timing of the two X chromosomes was similar to autosomes, while replication of the single $\mathrm{X}$ in male $\mathrm{Cl} 8$ cells was dramatically advanced. Basically no late replication is detected on the $\mathrm{X}$ chromosome in male cells $(P<2.2 \mathrm{e}-16)$ (Fig. 4A,B,D,E; Supplemental Fig. 8C).

Note that in Drosophila males, compensation of sexspecific differences in X-linked gene dosage is achieved by 
Table 1. Gene ontology terms of nonexpressed genes with advanced replication timing in Cl8 cells

\begin{tabular}{ll}
\hline Gene Ontology terms & $P$-value \\
\hline Wnt receptor signaling pathway, calcium modulating pathway; ventral midline development; compartment & \\
specification; spiracle morphogenesis, open tracheal system & \\
Sensory perception; dopamine metabolic process; catecholamine metabolic process; phenol metabolic & \\
process; indolalkylamine biosynthetic process; serotonin biosynthetic process; biogenic amine metabolic & 0.0161 \\
process; sensory perception of taste; indole derivative biosynthetic process & 0.0185 \\
Leg disc development; leg morphogenesis; limb morphogenesis; imaginal disc-derived leg morphogenesis; \\
$\quad$ leg segmentation; appendage segmentation; leg disc morphogenesis; imaginal disc-derived limb morphogenesis; \\
imaginal disc-derived leg joint morphogenesis; leg joint morphogenesis; establishment of ommatidial polarity \\
Neurotransmitter metabolic process; amino acid derivative metabolic process \\
Gut development; hindgut morphogenesis; ectodermal gut morphogenesis; gut morphogenesis; digestive \\
$\quad$ tract morphogenesis; fibroblast growth factor receptor signaling pathway \\
Wing disc pattern formation; imaginal disc pattern formation; neuroblast fate determination; neuroblast \\
$\quad$ fate commitment; neuroblast differentiation; wing disc anterior/posterior pattern formation \\
Segmentation
\end{tabular}

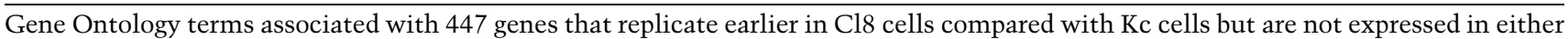
cell type (based on Affymetrix expression arrays; see the Supplemental Material). Gene Ontology terms and their $P$-values were calculated using GOstat (see the Supplemental Material).

doubling the expression from the single $\mathrm{X}$ chromosome and involves the activity of a male-specific dosage compensation complex (MSL complex) (Lucchesi et al. 2005). To test if the advanced replication timing is merely reflective of gender-specific transcriptional differences, we assessed replication timing differences in inactive genes or intergenic regions on the X chromosome. Surprisingly, we found that most of those regions show advanced replication timing in $\mathrm{Cl} 8$ cells (Supplemental Fig. 7B), even though they are not subject to transcriptional up-regulation and/or bound by the MSL complex or RNA Polymerase II (Fig. 4A; Alekseyenko et al. 2006). This is in agreement with the fact that dosage compensation does not involve activation of additional malespecific genes (Gilfillan et al. 2006), but instead achieves up-regulation of genes that are also active in females (Fig. $4 \mathrm{~A}$; Straub et al. 2005). Thus, the sites of transcription on the X chromosome are as similar between the two cell types as they are between autosomes. Furthermore, binding of the dosage compensation complex (DCC) is restricted to genes, which are already early replicating on the female X chromosome (Fig. 4A; Supplemental Fig. 7C). Thus, local DCC binding cannot account for replication timing differences. We conclude that unlike many autosomal regions, switching of the X-chromosomal regions to early replication often occurs outside of sites of active transcription and DCC recruitment.

\section{Acetylation of H4K16 marks early replicating regions on the male $X$}

We next asked if early replication of nontranscribed sequences on the male $\mathrm{X}$ could be explained by changes in histone modifications that affect chromatin structure. The dosage-compensated $\mathrm{X}$ chromosome is associated with highly elevated levels of acetylation of Lys 16 of histone $\mathrm{H} 4$ (H4K16ac) as measured by immunofluorescence, polytene staining, and chromatin immunoprecipitation (ChIP) (Turner et al. 1992; Smith et al. 2001;
Gilfillan et al. 2006; Kind et al. 2008). Importantly, acetylation of this particular lysine residue has been shown to directly interfere with higher-order chromatin compaction in vitro (Shogren-Knaak et al. 2006). In fact, acetylation of this residue leads to a more pronounced chromatin fiber decompaction than the removal of the entire $\mathrm{H} 4$ tail (Robinson et al. 2008). Increased acetylation of H4K16 at the dosage-compensated X chromosome in Drosophila also leads to a decondensed polytene chromosome in vivo (Corona et al. 2002). Importantly, however, H4K16 acetylation is also present on autosomes in flies (Bell et al. 2007; Kind et al. 2008) and at accessible chromatin in human cells in vivo (Shogren-Knaak et al. 2006).

To address a possible link between H4K16ac and early replication, we generated genome-wide profiles by ChIPchip in both $\mathrm{Kc}$ and $\mathrm{Cl} 8$ cells. We observed a global enrichment of this modification at the single male $\mathrm{X}$ chromosome (Fig. 4C; Supplemental Fig. 8A,B), which is in agreement with previously published immunofluorescence data (Turner et al. 1992). Furthermore, this mark is not exclusive to the dosage-compensated $\mathrm{X}$ as it is also present at active promoters on autosomal genes and on the female X (Fig. 4F; Supplemental Fig. 9A,B), consistent with previous reports (Bell et al. 2007).

At the dosage-compensated male $\mathrm{X}$ chromosome, H4K16ac is mostly abundant throughout active genes (Fig. 4G), in agreement with single-gene studies (Smith et al. 2001; Gilfillan et al. 2006; Bell et al. 2008). However, while most prevalent at active genes, the increased acetylation extends beyond the sites of dosage compensation and active transcription throughout the chromosome (Fig. 4A,C). Indeed, enrichment at inactive genes on the dosage-compensated $\mathrm{X}$ chromosome is as high as at active genes on autosomes (Fig. 4A, G; Supplemental Fig. 9B). Surprisingly, H4K16ac at these transcriptionally inactive genes reflects precisely their timing of replication: Nontranscribed early replicating genes have significantly higher acetylation levels than the few inactive late 
replicating genes $(P$-value $<2.2 \mathrm{e}-16)$ (Fig. 4G). This is not the case when assessing the distribution of RNA Polymerase II across genes (Supplemental Fig. 9C,D), which suggests a correlation between chromatin and replication timing independent of ongoing transcription. A reduction of endogenous levels of the acetyltransferase MOF, which is responsible for $\mathrm{X}$-specific $\mathrm{H} 4 \mathrm{~K} 16 \mathrm{ac}$ in males leads to a strong reduction of cells in S phase (Supplemental Fig. 12). This cell cycle exit precludes a more direct assessment of the contribution of H4K16ac to the observed male-specific replication timing.
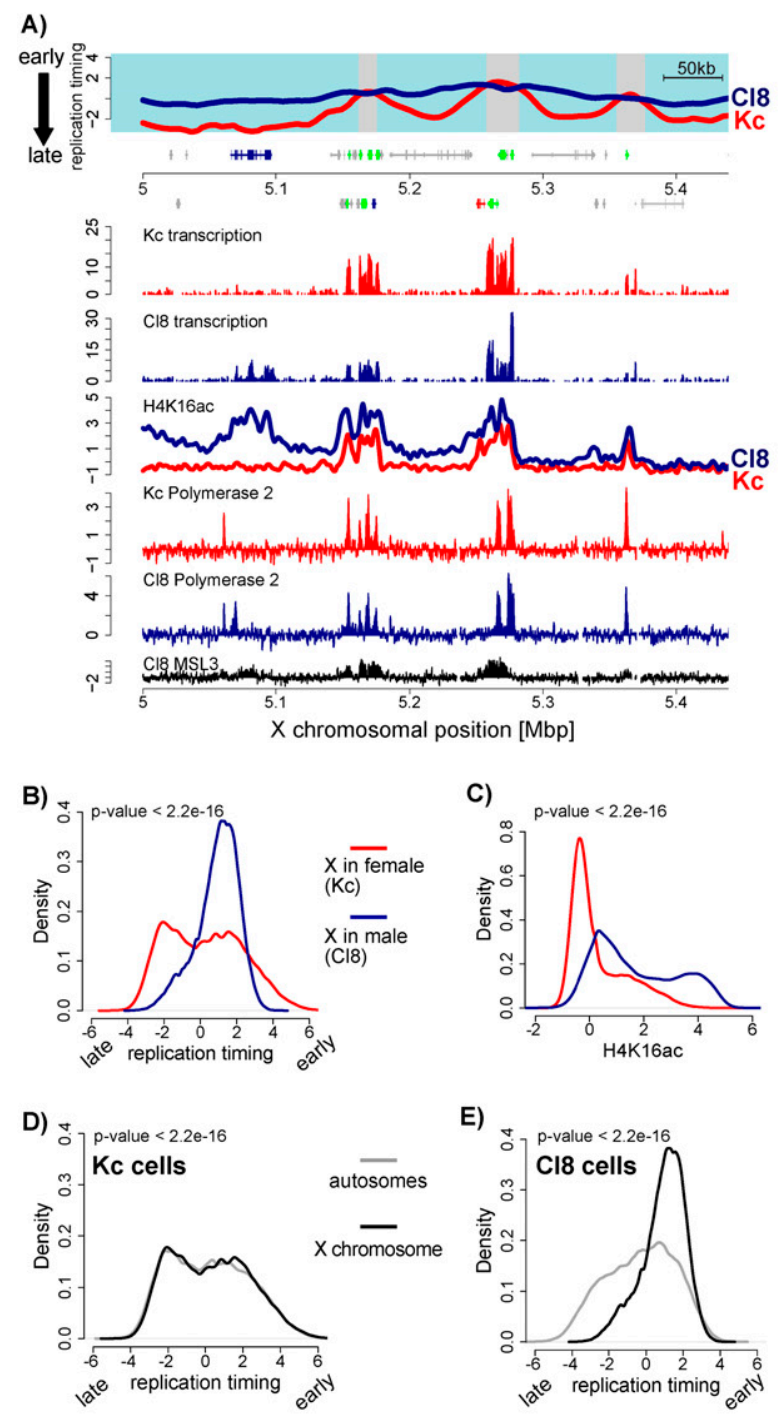

E)
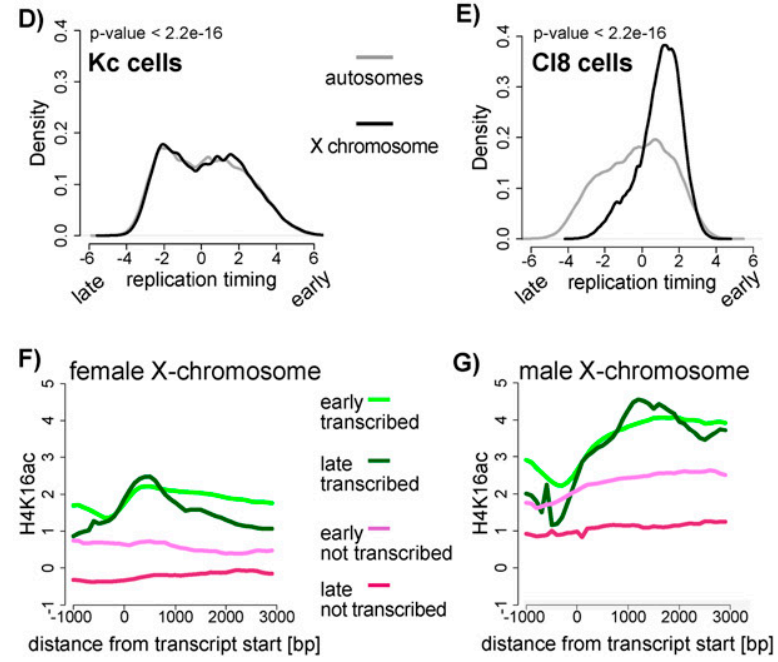

In summary, the dosage-compensated X chromosome shows chromosome-wide advanced replication, which relates most strongly with a local increase of H4K16ac outside of sites of dosage compensation.

\section{Acetylation of H4K16 marks early replicating regions and sites of initiation on autosomes}

An analysis of autosomal patterns of H4K16ac in relation to transcription and replication reveals that $\mathrm{H} 4 \mathrm{~K} 16 \mathrm{ac}$ is more abundant promoter-proximal at active genes (Supplemental Fig. 9A,B), in agreement with a function of this mark in transcriptional activation (Bell et al. 2007; Kind et al. 2008). However, even at inactive autosomal genes, zones of early replication also bear higher levels of H4K16 acetylation (Supplemental Fig. 9A,B). For example, H4K16ac is substantially increased at a nongenic and nontranscribed site in the wingless locus in $\mathrm{Cl} 8$ cells and within an E:L differentially replicating region on chromosome $2 \mathrm{~L}$ in $\mathrm{Kc}$ cells (Supplemental Figs. 6B, 10A). This enrichment of $\mathrm{H} 4 \mathrm{~K} 16 \mathrm{ac}$ at sites of early replication also does not coincide with RNA Polymerase II binding (Supplemental Figs. 9C, 10A), again supporting its independence of transcription.

Thus, in analogy to the situation at the dosage-compensated $\mathrm{X}$, early replicated regions on autosomes show increased levels of H4K16 acetylation even when not transcribed. Finally, we note that the autosomal enrichment is particularly strong at zones of initiation. This is directly evident in a single chromosomal profile (Fig. 5A) and further supported by global analysis $(P$-value $<2.2 \mathrm{e}$ 16) (Supplemental Fig. 10B). Importantly, this conclusion can also be drawn from the analysis of nontranscribed

Figure 4. Early replication timing of the male $\mathrm{X}$ chromosome. (A) Replication timing and transcription of a representative region on the $\mathrm{X} . \mathrm{Cl} 8$ is shown in blue and $\mathrm{Kc}$ is shown in red (similar to Fig. 3A). In addition, H4K16ac and RNA polymerase II profiles are displayed for Kc (red line) and Cl8 (blue line) cells (Affymetrix tiling arrays). Previously published MSL3 binding data in Cl8 cells (Alekseyenko et al. 2006) are shown in black. (B) Quantitative comparison of replication timing between male and female $\mathrm{X}$ chromosomes. Shown is the frequency of array probes for any given replication timing value ( $X$-axis) separately for the $\mathrm{X}$ in male $(\mathrm{Cl} 8$, blue line) and for the $\mathrm{X}$ in female $(\mathrm{Kc}$, red line). This density plot shows that most of the male $\mathrm{X}$ replicates early (above zero), while the female $\mathrm{X}$ replicates similarly to autosomes. $(C)$ Comparison of H4K16 acetylation for all Xlinked array probes similar to $B$. This density plot shows that the male $\mathrm{X}$ is strongly enriched for H4K16 acetylation. $(D, E)$ Density plot of replication timing on the $\mathrm{X}$ chromosome versus autosomes in female Kc cells $(D)$ and in male Cl8 cells $(E)$. Pvalues were calculated using the Wilcoxon rank-sum test. $(F)$ Average signal for H4K16ac in Kc cells at genes. Genes were grouped according to replication timing and transcriptional activity into "active, early replicating," (green line), "active, late replicating," (dark-green line), "inactive, early replicating," (violet line), and "inactive, late replicating" (red line). Genes were aligned at their start sites, and signals were averaged (see the Supplemental Material). ( $G$ ) Similar analysis as in $F$ for male cells $(\mathrm{Cl} 8)$. Note that the male $\mathrm{X}$ chromosome contains higher H4K16 acetylation signals throughout active genes, but also in the gene body of early replicating nontranscribed genes. 


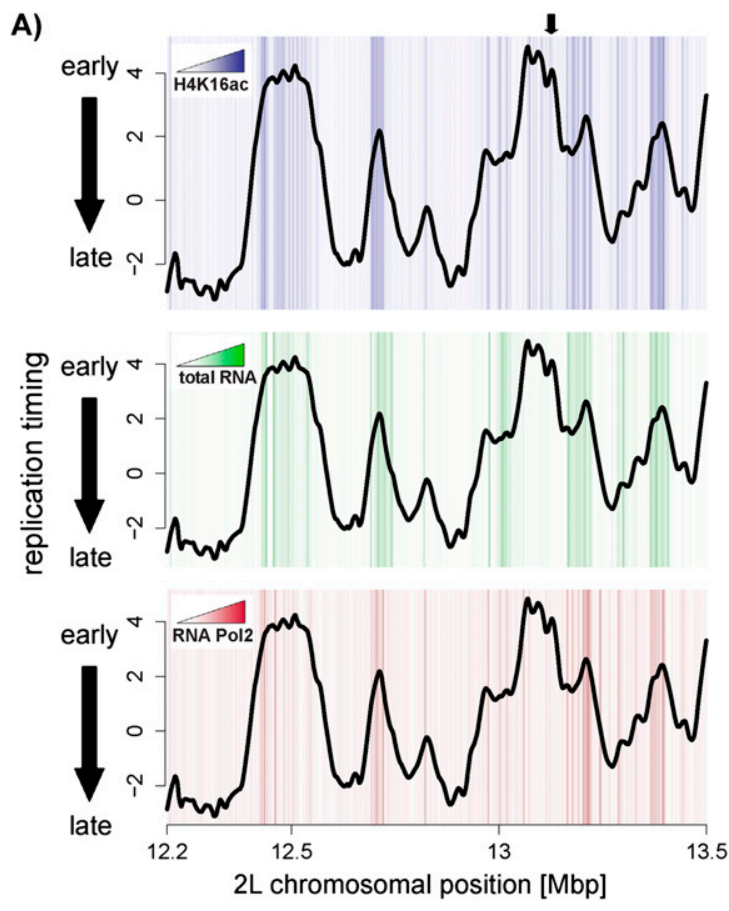

B)
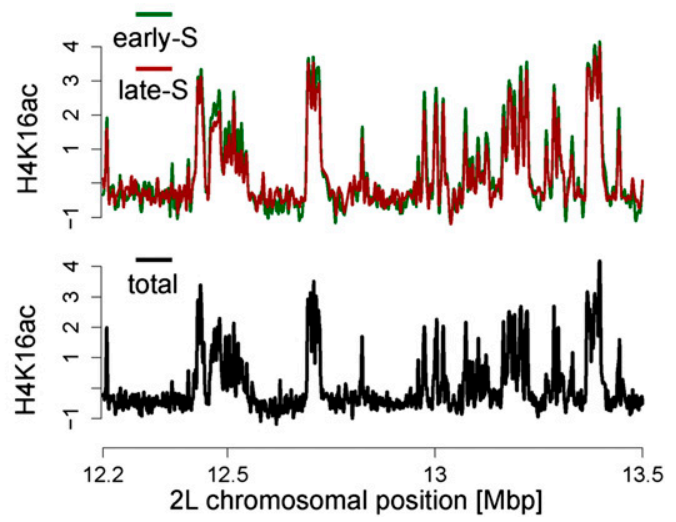

Figure 5. H4K16ac is enriched at initiation zones on autosomes. (A) Shown is a Kc replication timing profile (line) with a heat map illustrating H4K16 acetylation (top graph), transcription (middle graph), or RNA Polymerase II (bottom graph) in the background. This reveals the presence of H4K16ac at sites of initiation, some of which are not transcribed. White indicates absence of enrichments, and darker colors indicate higher levels. The black arrow marks a region of replication initiation with high H4K16ac, but not RNA or Polymerase II levels. Quantification of these heat map data is provided in Supplemental Figure 10B-D. (B) Profiles of H4K16ac generated from cells that are in early-S phase (green) or late-S phase (red). These patterns are almost identical to the pattern generated from unsorted cells (black line) indicating that H4K16 acetylation levels are not S-phase-specific.

regions alone $(P$-value $<2.2 \mathrm{e}-16)$ (Fig. 5A; Supplemental Fig. 10D). This argues that this histone modification, and not transcription per se, is the better correlate for early initiation. It appears as if H4K16 acetylation on both autosomes as well as the dosage-compensated X chromosome is correlated with early replication.
Localized acetylation of H4K16 is present throughout $S$ phase

Histone acetylation has a very short half-lifetime and thus is thought to be the most dynamic histone modification (Waterborg 1998). We wanted to directly measure the distribution of H4K16 acetylation in S phase since the genome-wide profiles in unsynchronized Drosophila cells could be mostly dependent on cells in G1 or G2 (Fig. 1A; Supplemental Fig. 11A).

To determine the distribution of H4K16ac in early- and late-S phase, we sorted Kc cells after formaldehyde crosslink into early- and late-S phase and performed ChIP for H4K16ac in sorted cells (Supplemental Fig. 11A). Interestingly, we observed a similar H4K16ac pattern in earlycompared with late-S phase (Fig. 5B; Supplemental Fig. 11B). Both patterns are very similar to that observed in bulk analysis (Fig. 5B). These data suggest that despite the turnover of acetylation marks in vivo, histone $\mathrm{H} 4$ acetylation of Lys 16 is present during the $S$ phase of the cell cycle and does not relocalize during the progression of $\mathrm{S}$ phase. This remarkable conservation is compatible with a link between histone acetylation and replication timing.

\section{Discussion}

We provide a detailed analysis of replication timing of the Drosophila genome at 35-bp resolution, which reveals insights into the chromosomal organization of replication, its tissue dependency, and its interplay with chromatin and transcription. We provide evidence that replication initiation occurs in a discontinuous manner throughout $S$ phase. Tissue-specific replication timing manifests itself at the level of $\sim 100-\mathrm{kb}$ large domains and in only half of all cases can be accounted for by differential transcription. Furthermore, we show that replication can be controlled chromosome-wide, because the $\mathrm{X}$ chromosome lacks late replication specifically in males. Finally, we implicate H4K16 acetylation as a transcription-independent correlate of this early replication and as a chromatin mark highly abundant at zones of initiation throughout the cell cycle.

\section{Genomic organization of replication timing and initiation}

The high resolution of our replication timing profiles allowed us to identify zones of replication initiation throughout $S$ phase, which we confirmed in combination with measuring small nascent strand abundance. This revealed that sites of early initiation are rather distinct, which manifests in the timing profile as single peaks or a few peaks clustered together in early-S phase, followed by long stretches of the replication timing profile without changes in slope. Late initiation zones often reside in close proximity to other late initiation zones (Fig. 2A). The feature of distinct peaks of early initiation in Drosophila is very distinct from mammalian genomes, where many more sites of initiation of similar timing are clustered together, resulting in large regions up to several 
megabase pairs of early replication timing (Hiratani et al. 2008).

Interestingly, the frequency of initiation appears discontinuous with high rates in early-S, a reduced frequency in mid-S, and again increased appearance of initiation sites in late-S phase. The high frequency and proximity of latefiring initiation zones suggest that late regions are replicated by many proximal late-firing origins of replication. This finding is particularly interesting in light of a recent report that suggested the absence of a checkpoint to control for the completion of DNA replication before mitosis (Torres-Rosell et al. 2007). This would in turn require a mechanism that mediates rapid replication of unreplicated regions in late-S phase, which could be achieved by a promiscuous activation of many proximal origins. Interestingly, replicative stress that reduces replication fork progression leads to a decrease in interorigin distance through activation of normally dormant origins (Anglana et al. 2003; Woodward et al. 2006). It is conceivable that a similar situation is encountered in late replicating regions.

\section{Dynamic replication timing between distinct cell types}

Since the previously reported correlation between replication timing and transcription in Drosophila was not absolute (Schübeler et al. 2002), the percentage of the genome that replicates in a tissue-specific fashion remained to be tested quantitatively. For example, the general correlation could be driven by housekeeping genes that are active in most cells, resulting in a uniform replication timing program. Here we show that dynamic replication timing differs significantly between two Drosophila cell types, affecting at least $20 \%$ of autosomal DNA. We also show by two different methodologies that this plasticity of DNA replication coincides with transcription differences in only half of all cases.

Early replication was shown previously to correlate with transcription levels over $180 \mathrm{~kb}$, leading to the suggestion that replication timing integrates transcription over large regions (MacAlpine et al. 2004). Consistent with this model, we find that dynamic replication timing often occurs in large $(\sim 100 \mathrm{~kb})$ regions encompassing many genes. Interestingly, genes with related function often cluster together in the Drosophila genome (Boutanaev et al. 2002), and such clusters tend to be similarly $100 \mathrm{~kb}$ in size (Boutanaev et al. 2002; Spellman and Rubin 2002). In mammalian genomes, this clustering appears functionally related to chromatin structure (Gierman et al. 2007), suggesting that widespread open chromatin at developmentally regulated multigene loci could lead to early replication or vice versa (Gilbert 2002; Schwaiger and Schübeler 2006). This, in turn, might increase the potential of gene expression over large regions as in the case of genes important for wing disc development in Cl8 cells (Supplemental Fig. 6B), where early replication could render the locus poised for activation.

Localized differences in gene expression of a fraction of genes in a large region might also account for replication timing differences. Indeed, some, but not all, genes in differentially replicating regions are strongly differentially expressed between the two cell types. Thus, while gene expression could account for much of the observed changes on autosomes, a considerable fraction does not display transcriptional changes. It seems unlikely that our analysis missed such changes since we measured noncoding transcription as well as RNA polymerase abundance.

\section{H4K16 acetylation links chromatin with early replication and initiation}

The relation between replication timing and chromatin structure has been controversial. Transcription itself involves an opening of chromatin structure, and thus early replication could in many situations be downstream from transcriptional activation (Gilbert 2002; Danis et al. 2004; Aladjem 2007). However, previous work using injected plasmids suggested a role for early replication in mediating increased levels of histone acetylation (Zhang et al. 2002). This led to a model in which replication timing mediates an open chromatin structure required for transcription. This suggestion is compatible with our genome-wide analysis, where we observe a preferential location of H4K16ac not only to active genes, but also to early replicating regions that are not transcribed (Figs. 4, 5). It is possible that early replication and elevated $\mathrm{H} 4 \mathrm{~K} 16 \mathrm{ac}$ at inactive genes will result in a more open chromatin confirmation compared with late replicating inactive genes. This might render them more responsive to downstream activating cues, and thus replication timing could modulate the sensitivity to activators. This process could also function in maintenance of an active state through cell division (Schwaiger and Schübeler 2006). Importantly, however, this mechanism does not override the parallel process of transcription-coupled acetylation, as late replicating genes that are actively transcribed are still hyperacetylated (Fig. 4F,G).

Interestingly, we also observe a strong abundance of H4K16ac at sites of initiation during S phase (Fig. 5). Several single-gene studies have suggested a positive function of histone acteylation for origin activity (Lin et al. 2003; Aggarwal and Calvi 2004; Danis et al. 2004; Calvi et al. 2007; Hartl et al. 2007; Goren et al. 2008). Other reports, however, did not support this model (Prioleau et al. 2003; Dazy et al. 2006; Gregoire et al. 2006). Recent maps of human replication initiation suggest that early origins are marked by H3K9/K14 acetylation (Lucas et al. 2007). However, no genome-wide correlation between active chromatin marks and early origin firing was observed in S. cerevisiae (Nieduszynski et al. 2006), where specific sequences function as origins of replication. Here we identified a preferential localization of H4K16ac to initiation zones throughout the Drosophila genome compatible with a function of acetylation. In this study, we focused on acetylation of H4K16 because this residue has been functionally linked to higher-order chromatin compaction and chromatin opening on the dosage-compensated X in Drosophila (Corona et al. 2002; Shogren-Knaak et al. 2006; Robinson et al. 2008; Suganuma et al. 2008). 
It has been proposed that origins of replication lie frequently between promoters of active genes (MacAlpine and Bell 2005; Huvet et al. 2007), which would make transcription and replication fork progression co-oriented (Huvet et al. 2007). Furthermore, transcription and replication are thought to be coordinated in the nucleus (Schwaiger and Schübeler 2006; Aladjem 2007) to be spatially and temporally separated. It thus seems plausible that the enrichment of $\mathrm{H} 4 \mathrm{~K} 16 \mathrm{ac}$ in initiation zones reflects location between highly acetylated, active promoters. According to this model, proximity to active promoters would result in an open chromatin confirmation through increased H4K16ac, which in turn enhances origin firing.

Importantly, however, we also observe enrichment for $\mathrm{H} 4 \mathrm{~K} 16 \mathrm{ac}$ at initiation zones that are not proximal to active genes (Fig. 5), which argues against a simple process that is solely transcription-coupled. Open chromatin structure, reflected and potentially even mediated by H4K16ac, could make DNA more accessible for efficient initiation of DNA replication and thus provide a sequence-independent component that could contribute to origin localization and activity. While these are testable models, they do require a fine-mapping of actual origins at a resolution higher than our detection of zones of initiation at the level of several kilobases.

\section{Absence of late replication of the male X chromosome reflects transcription-independent changes in chromatin}

Our analysis reveals the almost complete absence of late replication on the single X chromosome in male Drosophila cells. About $90 \%$ of female late replicating regions on the $\mathrm{X}$ replicate early in males, while autosomes show no advanced replication (Fig. 4; Supplemental Fig. 8). Such chromosome-wide advance in replication timing has not been observed previously. In mammals, transcriptional inactivation of one of the female $\mathrm{X}$ chromosomes correlates with its late replication, reflecting the efficient silencing of this chromosome and increased chromatin compaction (Lucchesi et al. 2005). In contrast, dosage compensation in flies involves the twofold up-regulation of genes already active in females (Straub et al. 2005) and an open chromatin state mediated by H4K16ac (Corona et al. 2002). Interestingly, we show that advanced replication of the dosage-compensated X occurs mostly outside of transcriptionally activated regions and thus is unlikely to be accounted for by transcriptional changes. Importantly, the local increases in H4K16ac, which we detect throughout the male $\mathrm{X}$ chromosome, can be directly related to this loss of late replication. Reduction of the responsible Histone-Acetyltransferase Mof leads to a block in cell division, making it difficult to test this model. Notably, we did detect slightly delayed replication of the X chromosome in the few cells that were in S phase in the knockdown population (data not shown). While this is compatible with a model that Mof-mediated H4K16 acetylation advances replication of intergenic regions on the male X chromosome, the predominant effect on the cell cycle precluded further analysis.
This suggests a transcription-independent, chromatindependent process, which leads to early replication chromosome-wide. While this likely reflects a different chromatin compaction, it is tempting to speculate that it also reflects a particular nuclear organization as the dosagecompensated $\mathrm{X}$ chromosome has been shown to associate directly with nuclear pores (Mendjan et al. 2006).

\section{Concluding remarks}

Together our findings provide new principles of the replication timing program of the Drosophila genome and its dynamics relative to histone acetylation and transcription. Our data further support a model in which open chromatin structure is a general feature of early replication timing and could potentially even advance replication of entire chromosomes.

\section{Materials and methods}

\section{Tissue culture and BrdU labeling}

Drosophila Kc cells were kept in HyQ-SFX (Hyclone). Clone8 $(\mathrm{Cl} .8+)$ cells were kept in Shields and Sang medium (Sigma), supplemented with $12.5 \mathrm{IU} / 100 \mathrm{~mL}$ insulin, $2 \%$ heat-inactivated FCS, and $2.5 \%$ fly extract (Peel et al. 1990). S2 cell culture and RNAi were performed as described (Bell et al. 2007). MOF knockdown cells were analyzed $5 \mathrm{~d}$ after initial addition of dsRNA. For labeling of newly synthesized DNA, we added BrdU (Sigma) to a logarithmically growing culture at a final concentration of $50 \mu \mathrm{M}$. After $60 \mathrm{~min}$ of incorporation time, we added Triton X-100 to a final concentration of $0.1 \%$ and DAPI to a final concentration of $3 \mu \mathrm{g} / \mathrm{mL}$ for $5 \mathrm{~min}$ at room temperature. Cells were immediately used for fractionation.

\section{Cell cycle fractionation and isolation of BrdU-labeled DNA}

We sorted cells into S-phase fractions on the basis of DNA content using fluorescent-activated cell sorting (FACS). We collected 60,000 cells from each fraction directly into lysis buffer. DNA was purified, sonicated, denatured, and immunoprecipitated with an antibody specific for BrdU as described (Schübeler et al. 2002), but with two consecutive rounds of immunoprecipitation.

\section{Transcription analysis}

Total RNA was isolated using Trizol (Invitrogen) and further purified (RNeasy kit; Qiagen). For hybridization to Affymetrix tiling arrays, we made double-stranded cDNA by performing two rounds of cDNA synthesis using random primers and addition of $2 \mathrm{mM}$ dUTPs using the GeneChip WT Double-Stranded cDNA Synthesis Kit (Affymetrix). cDNA was fragmented and endlabeled using the GeneChip WT Double-Stranded DNA Terminal labeling Kit (Affymetrix) and hybridized to GeneChip Drosophila Tiling 1.0R arrays (Affymetrix) according to the manufacturer's instructions. For hybridization to expression arrays, cDNA synthesis and hybridizations were carried out according to standard Affymetrix procedures.

\section{Nascent strand analysis}

Nascent strand DNA in a size range of 1000 to 2000 bp was isolated from logarithmically growing Kc cells by alkaline gel 
electrophoresis (Gray et al. 2007). Genomic DNA from Kc cells in $\mathrm{G}_{2}$ phase (isolated by FACS) was used as a control. The enrichments of nascent DNA compared with genomic DNA for sequences within and distal to the DNA-Pol $\alpha$ origin were analyzed using real-time PCR (Supplemental Fig. 4A).

\section{ChIP}

ChIP for H4K16 acetylation and RNA Polymerase II was carried out as described (Bell et al. 2007). For ChIP with S-phase sorted cells, DNA was labeled with Hoechst in living cells for $30 \mathrm{~min}$, then proteins and DNA were cross-linked according to standard procedures (Bell et al. 2007) followed by FACS sorting based on DNA content (Hoechst) in Kc cell medium with added protease inhibitors. ChIP was performed as on asynchronous cells. Input material was taken from the corresponding S-phase fraction. Immunoprecipitated DNA from early-S phase was hybridized to arrays and compared with hybridizations of early-S phase Input DNA and similarly late-S IP was compared with late-S input DNA.

\section{Target sequence amplification and microarray processing}

For microarray hybridization, immunoprecipitated DNA was amplified (Schübeler et al. 2002). For nascent DNA, only one round of 3' degenerate primer annealing for subsequent linear amplification was done. Before labeling and hybridization to arrays, several control genes were tested by qPCR. For use with Affymetrix tiling arrays, dUTP was incorporated into the amplification reaction at $2 \mathrm{mM}$, the amplified DNA was fragmented and end-labeled using the GeneChip WT Double-Stranded DNA Terminal labeling Kit (Affymetrix) and hybridized to GeneChip Drosophila Tiling 1.0R or 2.0R arrays (Affymetrix) according to the manufacturer's instructions. For Nimblegen arrays (used as a platform-independent control for Kc replication timing; Steve Henikoff custom design, 2005-04-20_Dros_60mer_ChIP) (Mito et al. 2005), labeling, hybridization, and data extraction were performed by NimbleGen systems, including dye swaps. All microarray experiments were carried out in at least two biological replicates. Detailed descriptions of computational array analysis are provided in the Supplemental Material. All data sets are deposited at NCBI GEO (http://www.ncbi.nlm.nih.gov/geo; GSE13328) (Edgar et al. 2002), and at our Web site (http:// www.fmi.ch/groups/schubeler.d/web/data.html).

\section{Acknowledgments}

We thank Antoine Peters, Susan Gasser, Kenji Shimada, and members of the laboratory for helpful comments on the manuscript, and Steven Gray and members of the laboratory of David Gilbert for advice on nascent DNA and replication timing analysis. We are grateful to Deborah Cottam for providing the $\mathrm{Cl} 8$ cell line, and to Wei Li for providing scripts for MAT analysis. M.S. was supported by a predoctoral fellowship of the Boehringer Ingelheim Fonds. Research in the laboratory of D.S. is supported by the Novartis Research Foundation, by the European Union (NoE "The Epigenome" LSHG-CT-2004-503433 and LSHG-CT2006-037415), and the EMBO Young Investigator program.

\section{References}

Aggarwal, B.D. and Calvi, B.R. 2004. Chromatin regulates origin activity in Drosophila follicle cells. Nature 430: 372-376.

Aladjem, M.I. 2007. Replication in context: Dynamic regulation of DNA replication patterns in metazoans. Nat. Rev. Genet. 8: 588-600.
Aladjem, M.I., Rodewald, L.W., Kolman, J.L., and Wahl, G.M. 1998. Genetic dissection of a mammalian replicator in the human $\beta$-globin locus. Science 281: 1005-1009.

Alekseyenko, A.A., Larschan, E., Lai, W.R., Park, P.J., and Kuroda, M.I. 2006. High-resolution ChIP-chip analysis reveals that the Drosophila MSL complex selectively identifies active genes on the male X chromosome. Genes \& Dev. 20: $848-857$.

Anglana, M., Apiou, F., Bensimon, A., and Debatisse, M. 2003. Dynamics of DNA replication in mammalian somatic cells: Nucleotide pool modulates origin choice and interorigin spacing. Cell 114: 385-394.

Aparicio, J.G., Viggiani, C.J., Gibson, D.G., and Aparicio, O.M. 2004. The Rpd3-Sin3 histone deacetylase regulates replication timing and enables intra-S origin control in Saccharomyces cerevisiae. Mol. Cell. Biol. 24: 4769-4780.

Audit, B., Nicolay, S., Huvet, M., Touchon, M., d'AubentonCarafa, Y., Thermes, C., and Arneodo, A. 2007. DNA replication timing data corroborate in silico human replication origin predictions. Phys. Rev. Lett. 99: 248102. doi: 10.1103/PhysRevLett.99.248102.

Bell, O., Wirbelauer, C., Hild, M., Scharf, A.N., Schwaiger, M., MacAlpine, D.M., Zilbermann, F., van Leeuwen, F., Bell, S.P., Imhof, A., et al. 2007. Localized H3K36 methylation states define histone H4K16 acetylation during transcriptional elongation in Drosophila. EMBO J. 26: 4974-4984.

Bell, O., Conrad, T., Kind, J., Wirbelauer, C., Akhtar, A., and Schübeler, D. 2008. Transcription-coupled methylation of histone $\mathrm{H} 3$ at lysine 36 regulates dosage compensation by enhancing recruitment of the MSL complex in Drosophila melanogaster. Mol. Cell. Biol. 28: 3401-3409.

Boutanaev, A.M., Kalmykova, A.I., Shevelyov, Y.Y., and Nurminsky, D.I. 2002. Large clusters of co-expressed genes in the Drosophila genome. Nature 420: 666-669.

Calvi, B.R., Byrnes, B.A., and Kolpakas, A.J. 2007. Conservation of epigenetic regulation, ORC binding and developmental timing of DNA replication origins in the genus Drosophila. Genetics 177: 1291-1301.

Cimbora, D.M., Schübeler, D., Reik, A., Hamilton, J., Francastel, C., Epner, E.M., and Groudine, M. 2000. Long-distance control of origin choice and replication timing in the human $\beta$-globin locus are independent of the locus control region. Mol. Cell. Biol. 20: 5581-5591.

Corona, D.F., Clapier, C.R., Becker, P.B., and Tamkun, J.W. 2002. Modulation of ISWI function by site-specific histone acetylation. EMBO Rep. 3: 242-247.

Danis, E., Brodolin, K., Menut, S., Maiorano, D., Girard-Reydet, C., and Mechali, M. 2004. Specification of a DNA replication origin by a transcription complex. Nat. Cell Biol. 6: 721-730.

Dazy, S., Gandrillon, O., Hyrien, O., and Prioleau, M.N. 2006. Broadening of DNA replication origin usage during metazoan cell differentiation. EMBO Rep. 7: 806-811.

Dijkwel, P.A., Mesner, L.D., Levenson, V.V., d'Anna, J., and Hamlin, J.L. 2000. Dispersive initiation of replication in the Chinese hamster rhodopsin locus. Exp. Cell Res. 256: 150-157.

Echalier, G. 1997. Drosophila cells in culture , . Academic Press, New York.

Edgar, R., Domrachev, M., and Lash, A.E. 2002. Gene Expression Omnibus: NCBI gene expression and hybridization array data repository. Nucleic Acids Res. 30: 207-210.

Gierman, H.J., Indemans, M.H., Koster, J., Goetze, S., Seppen, J., Geerts, D., van Driel, R., and Versteeg, R. 2007. Domainwide regulation of gene expression in the human genome. Genome Res. 17: 1286-1295. 
Gilbert, D.M. 2002. Replication timing and transcriptional control: Beyond cause and effect. Curr. Opin. Cell Biol. 14: 377-383.

Gilbert, D.M. and Cohen, S.N. 1987. Bovine papilloma virus plasmids replicate randomly in mouse fibroblasts throughout S phase of the cell cycle. Cell 50: 59-68.

Gilfillan, G.D., Straub, T., de Wit, E., Greil, F., Lamm, R., van Steensel, B., and Becker, P.B. 2006. Chromosome-wide genespecific targeting of the Drosophila dosage compensation complex. Genes \& Dev. 20: 858-870.

Goren, A., Tabib, A., Hecht, M., and Cedar, H. 2008. DNA replication timing of the human $\beta$-globin domain is controlled by histone modification at the origin. Genes \& Dev. 22: 1319-1324.

Gray, S.J., Gerhardt, J., Doerfler, W., Small, L.E., and Fanning, E. 2007. An origin of DNA replication in the promoter region of the human fragile $\mathrm{X}$ mental retardation (FMR1) gene. Mol. Cell. Biol. 27: 426-437.

Gregoire, D., Brodolin, K., and Mechali, M. 2006. HoxB domain induction silences DNA replication origins in the locus and specifies a single origin at its boundary. EMBO Rep. 7: 812816.

Greil, F., van der Kraan, I., Delrow, J., Smothers, J.F., de Wit, E., Bussemaker, H.J., van Driel, R., Henikoff, S., and van Steensel, B. 2003. Distinct HP1 and Su/var)3-9 complexes bind to sets of developmentally coexpressed genes depending on chromosomal location. Genes \& Dev. 17: 2825-2838.

Hansen, R.S., Canfield, T.K., Lamb, M.M., Gartler, S.M., and Laird, C.D. 1993. Association of fragile X syndrome with delayed replication of the FMR1 gene. Cell 73: 1403-1409.

Hartl, T., Boswell, C., Orr-Weaver, T.L., and Bosco, G. 2007. Developmentally regulated histone modifications in Drosophila follicle cells: Initiation of gene amplification is associated with histone $\mathrm{H} 3$ and $\mathrm{H} 4$ hyperacetylation and H1 phosphorylation. Chromosoma 116: 197-214.

Hiratani, I., Leskovar, A., and Gilbert, D.M. 2004. Differentiation-induced replication-timing changes are restricted to ATrich/long interspersed nuclear element (LINE)-rich isochores. Proc. Natl. Acad. Sci. 101: 16861-16866.

Hiratani, I., Ryba, T., Itoh, M., Yokochi, T., Schwaiger, M., Chang, C.W., Lyou, Y., Townes, T.M., Schübeler, D., and Gilbert, D.M. 2008. Global reorganization of replication domains during embryonic stem cell differentiation. PLOS Biol. 6: e245. doi: 10.1371/journal.pbio.0060245.

Huvet, M., Nicolay, S., Touchon, M., Audit, B., d'AubentonCarafa, Y., Arneodo, A., and Thermes, C. 2007. Human gene organization driven by the coordination of replication and transcription. Genome Res. 17: 1278-1285.

Kind, J., Vaquerizas, J.M., Gebhardt, P., Gentzel, M., Luscombe, N.M., Bertone, P., and Akhtar, A. 2008. Genome-wide analysis reveals MOF as a key regulator of dosage compensation and gene expression in Drosophila. Cell 133: 813-828.

Lin, C.M., Fu, H., Martinovsky, M., Bouhassira, E., and Aladjem, M.I. 2003. Dynamic alterations of replication timing in mammalian cells. Curr. Biol. 13: 1019-1028.

Liu, C.L., Kaplan, T., Kim, M., Buratowski, S., Schreiber, S.L., Friedman, N., and Rando, O.J. 2005. Single-nucleosome mapping of histone modifications in S. cerevisiae. PLoS Biol. 3: e328. doi: 10.1371/journal.pbio.0030328.

Lucas, I., Palakodeti, A., Jiang, Y., Young, D.J., Jiang, N., Fernald, A.A., and Le Beau, M.M. 2007. High-throughput mapping of origins of replication in human cells. EMBO Rep. 8: 770-777.

Lucchesi, J.C., Kelly, W.G., and Panning, B. 2005. Chromatin remodeling in dosage compensation. Annu. Rev. Genet. 39: 615-651.

MacAlpine, D.M. and Bell, S.P. 2005. A genomic view of eukaryotic DNA replication. Chromosome Res. 13: 309-326.
MacAlpine, D.M., Rodriguez, H.K., and Bell, S.P. 2004. Coordination of replication and transcription along a Drosophila chromosome. Genes \& Dev. 18: 3094-3105.

Mendjan, S., Taipale, M., Kind, J., Holz, H., Gebhardt, P., Schelder, M., Vermeulen, M., Buscaino, A., Duncan, K., Mueller, J., et al. 2006. Nuclear pore components are involved in the transcriptional regulation of dosage compensation in Drosophila. Mol. Cell 21: 811-823.

Mito, Y., Henikoff, J.G., and Henikoff, S. 2005. Genome-scale profiling of histone H3.3 replacement patterns. Nat. Genet. 37: 1090-1097.

Muse, G.W., Gilchrist, D.A., Nechaev, S., Shah, R., Parker, J.S., Grissom, S.F., Zeitlinger, J., and Adelman, K. 2007. RNA polymerase is poised for activation across the genome. Nat. Genet. 39: 1507-1511.

Nieduszynski, C.A., Knox, Y., and Donaldson, A.D. 2006. Genome-wide identification of replication origins in yeast by comparative genomics. Genes \& Dev. 20: 1874-1879.

Norio, P., Kosiyatrakul, S., Yang, Q., Guan, Z., Brown, N.M., Thomas, S., Riblet, R., and Schildkraut, C.L. 2005. Progressive activation of DNA replication initiation in large domains of the immunoglobulin heavy chain locus during B cell development. Mol. Cell 20: 575-587.

Peel, D.J., Johnson, S.A., and Milner, M.J. 1990. The ultrastructure of imaginal disc cells in primary cultures and during cell aggregation in continuous cell lines. Tissue Cell 22: 749-758.

Perry, P., Sauer, S., Billon, N., Richardson, W.D., Spivakov, M., Warnes, G., Livesey, F.J., Merkenschlager, M., Fisher, A.G., and Azuara, V. 2004. A dynamic switch in the replication timing of key regulator genes in embryonic stem cells upon neural induction. Cell Cycle 3: 1645-1650.

Prioleau, M.N., Gendron, M.C., and Hyrien, O. 2003. Replication of the chicken $\beta$-globin locus: Early-firing origins at the $5^{\prime}$ HS4 insulator and the $\rho$ - and $\beta$ A-globin genes show opposite epigenetic modifications. Mol. Cell. Biol. 23: 3536-3549.

Raghuraman, M.K., Winzeler, E.A., Collingwood, D., Hunt, S., Wodicka, L., Conway, A., Lockhart, D.J., Davis, R.W., Brewer, B.J., and Fangman, W.L. 2001. Replication dynamics of the yeast genome. Science 294: 115-121.

Robinson, P.J., An, W., Routh, A., Martino, F., Chapman, L., Roeder, R.G., and Rhodes, D. 2008. $30 \mathrm{~nm}$ chromatin fibre decompaction requires both H4-K16 acetylation and linker histone eviction. J. Mol. Biol. 381: 816-825.

Sasaki, T., Sawado, T., Yamaguchi, M., and Shinomiya, T. 1999. Specification of regions of DNA replication initiation during embryogenesis in the 65-kilobase DNApola-dE2F locus of Drosophila melanogaster. Mol. Cell. Biol. 19: 547-555.

Schübeler, D., Francastel, C., Cimbora, D.M., Reik, A., Martin, D.I., and Groudine, M. 2000. Nuclear localization and histone acetylation: A pathway for chromatin opening and transcriptional activation of the human $\beta$-globin locus. Genes \& Dev. 14: 940-950.

Schübeler, D., Scalzo, D., Kooperberg, C., van Steensel, B., Delrow, J., and Groudine, M. 2002. Genome-wide DNA replication profile for Drosophila melanogaster: A link between transcription and replication timing. Nat. Genet. 32: 438-442.

Schübeler, D., MacAlpine, D.M., Scalzo, D., Wirbelauer, C., Kooperberg, C., van Leeuwen, F., Gottschling, D.E., O'Neill, L.P., Turner, B.M., Delrow, J., et al. 2004. The histone modification pattern of active genes revealed through genome-wide chromatin analysis of a higher eukaryote. Genes \& Dev. 18: 1263-1271. 
Schwaiger, M. and Schübeler, D. 2006. A question of timing: Emerging links between transcription and replication. Curr. Opin. Genet. Dev. 16: 177-183.

Shogren-Knaak, M., Ishii, H., Sun, J.M., Pazin, M.J., Davie, J.R., and Peterson, C.L. 2006. Histone H4-K16 acetylation controls chromatin structure and protein interactions. Science 311: 844-847.

Smith, E.R., Allis, C.D., and Lucchesi, J.C. 2001. Linking global histone acetylation to the transcription enhancement of $\mathrm{X}$ chromosomal genes in Drosophila males. J. Biol. Chem. 276: 31483-31486.

Spellman, P.T. and Rubin, G.M. 2002. Evidence for large domains of similarly expressed genes in the Drosophila genome. J. Biol. 1: 5. doi: 10.1186/1475-4924-1-5.

Straub, T., Gilfillan, G.D., Maier, V.K., and Becker, P.B. 2005. The Drosophila MSL complex activates the transcription of target genes. Genes \& Dev. 19: 2284-2288.

Suganuma, T., Gutierrez, J.L., Li, B., Florens, L., Swanson, S.K., Washburn, M.P., Abmayr, S.M., and Workman, J.L. 2008. ATAC is a double histone acetyltransferase complex that stimulates nucleosome sliding. Nat. Struct. Mol. Biol. 15: :364-372.

Torres-Rosell, J., De Piccoli, G., Cordon-Preciado, V., Farmer, S., Jarmuz, A., Machin, F., Pasero, P., Lisby, M., Haber, J.E., and Aragon, L. 2007. Anaphase onset before complete DNA replication with intact checkpoint responses. Science 315: 1411-1415.

Turner, B.M., Birley, A.J., and Lavender, J. 1992. Histone H4 isoforms acetylated at specific lysine residues define individual chromosomes and chromatin domains in Drosophila polytene nuclei. Cell 69: 375-384.

Vogelauer, M., Rubbi, L., Lucas, I., Brewer, B.J., and Grunstein, M. 2002. Histone acetylation regulates the time of replication origin firing. Mol. Cell 10: 1223-1233.

Waterborg, J.H. 1998. Dynamics of histone acetylation in Chlamydomonas reinhardtii. J. Biol. Chem. 273: 27602-27609.

White, E.J., Emanuelsson, O., Scalzo, D., Royce, T., Kosak, S., Oakeley, E.J., Weissman, S., Gerstein, M., Groudine, M., Snyder, M., et al. 2004. DNA replication-timing analysis of human chromosome 22 at high resolution and different developmental states. Proc. Natl. Acad. Sci. 101: 17771-17776.

Woodfine, K., Fiegler, H., Beare, D.M., Collins, J.E., McCann, O.T., Young, B.D., Debernardi, S., Mott, R., Dunham, I., and Carter, N.P. 2004. Replication timing of the human genome. Hum. Mol. Genet. 13: 191-202.

Woodfine, K., Beare, D.M., Ichimura, K., Debernardi, S., Mungall, A.J., Fiegler, H., Collins, V.P., Carter, N.P., and Dunham, I. 2005. Replication timing of human chromosome 6. Cell Cycle 4: 172-176.

Woodward, A.M., Gohler, T., Luciani, M.G., Oehlmann, M., Ge, X., Gartner, A., Jackson, D.A., and Blow, J.J. 2006. Excess Mcm2-7 license dormant origins of replication that can be used under conditions of replicative stress. J. Cell Biol. 173: 673-683.

Zeitlinger, J., Stark, A., Kellis, M., Hong, J.W., Nechaev, S., Adelman, K., Levine, M., and Young, R.A. 2007. RNA polymerase stalling at developmental control genes in the Drosophila melanogaster embryo. Nat. Genet. 39: 1512-1516.

Zhang, J., Xu, F., Hashimshony, T., Keshet, I., and Cedar, H. 2002. Establishment of transcriptional competence in early and late S phase. Nature 420: 198-202.

Zhou, J., Ashouian, N., Delepine, M., Matsuda, F., Chevillard, C., Riblet, R., Schildkraut, C.L., and Birshtein, B.K. 2002. The origin of a developmentally regulated Igh replicon is located near the border of regulatory domains for Igh replication and expression. Proc. Nat1. Acad. Sci. 99: 13693-13698. 


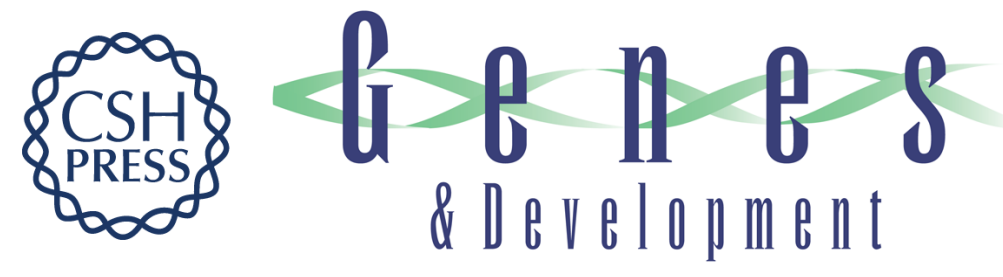

\section{Chromatin state marks cell-type- and gender-specific replication of the Drosophila genome}

Michaela Schwaiger, Michael B. Stadler, Oliver Bell, et al.

Genes Dev. 2009, 23:

Access the most recent version at doi:10.1101/gad.511809

Supplemental http://genesdev.cshlp.org/content/suppl/2009/03/05/23.5.589.DC1
Material

References This article cites 68 articles, 29 of which can be accessed free at: http://genesdev.cshlp.org/content/23/5/589.full.html\#ref-list-1

License

Email Alerting

Receive free email alerts when new articles cite this article - sign up in the box at the top Service right corner of the article or click here.

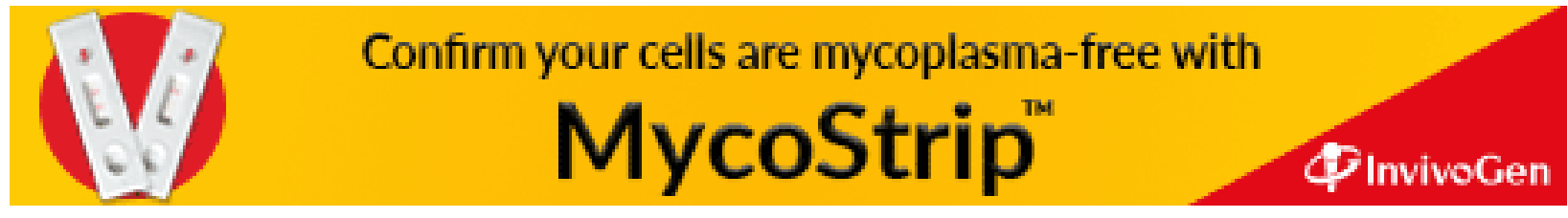

